\title{
Research on the Influence of High-tech Industry Specialization Agglomeration on Innovation Efficiency
}

\author{
Shuyang $\operatorname{Nan}^{1}$ \\ ${ }^{1}$ School of Economics and Management, Beijing Jiaotong University, Beijing, China
}

\begin{abstract}
In the new economic era with innovation as the first driving factor, high-tech industry, as an important industry support for innovation, its innovation efficiency will greatly affect the regional innovation level. In order to improve the innovation efficiency of the high-tech industry, the practice of accelerating the professional agglomeration of the industry has been widely adopted. What is the impact of high-tech industry specialization agglomeration on innovation level? Based on this, this paper constructs a theoretical analysis framework between industrial specialization agglomeration and innovation efficiency, and empirically analyzes it. The research results are as follows: there is an inverted U-shaped relationship between high-tech industry specialization agglomeration and innovation efficiency, that is, there is a specialized agglomeration scale, which makes industrial innovation efficiency reach the highest level. According to the empirical results, this paper provides a data level support for the proposal of industrial agglomeration policy.
\end{abstract}

\section{Introduction}

China's economy has been developed from rapid growth to high quality development and the construction of modern economic system is the urgent request of crossing the threshold. Innovation is the strategic support of construction of modern economic system. It is particularly important to study how to improve innovation efficiency, that is, how to get the most possible innovation output under the given innovation input.

With the gradual implementation of the national innovation-driven development strategy, the high-tech industry, characterized by high knowledge and technology density and high R\&D investment intensity, is gradually becoming an important industry support for innovation. The innovation efficiency of this industry is playing an increasingly important role in improving the regional innovation level.

In order to improve the innovation efficiency of hightech industry, all regions have adopted the practice of accelerating the specialization agglomeration of this industry. In earlier years, specialization of agglomeration mainly through industrial park and other traditional industry cluster model, but in recent years, the local government began to push around the industrial community and so on construction of a new mode of industrial agglomeration, such as, Chengu high-tech zone, located in Nanhai District, Foshan city, South park in Guangdong province, Shanghai Caohejing industrial community and so on.

Based on the above research background, when the agglomeration scale is studied in this paper, high-tech industrial agglomeration has a positive effect on regional innovation efficiency.

\section{Literature review}

Reviewing relevant literature, scholars have different views on the effectiveness of industry agglomeration. Relevant research conclusions of scholars are mainly divided into three categories. First, industry specialization agglomeration promotes innovation efficiency. For example, Lundvall believe that industrial agglomeration can drive regional innovation through spillover effects of knowledge and technology [1]. Neng Shen and Zengyao Zhao find that industrial agglomeration also plays a significant role in promoting innovation ability based on Chinese data [2]. Second, industry specialization agglomeration have a negative impact on innovation efficiency. For example, Katz demonstrate that specialization agglomeration is not conducive to the improvement of innovation efficiency by constructing monopoly model [3]. Caijiang Zhang et al. [4] and Changshi Chen et al.[5] all believe that specialization agglomeration inhibits regional innovation activities of high-tech industries. Third, some researchers believe that the influence of specialization agglomeration on innovation efficiency is U-shaped. Fritsch and Slavtchev find a U-shaped relationship between industrial specialization agglomeration and innovation efficiency, indicating the existence of Marshall and Jacobs externalities [6]. Yongjian Lai find that there was actually an inverted U-shaped relationship between specialization agglomeration and innovation efficiency, which promoted first and inhibited later [7]. According to Shasha Li et al., there is a significant inverted U-shaped relationship between industrial agglomeration and enterprise 
innovation output scale, and a significant U-shaped relationship between industrial agglomeration and enterprise innovation initiative [8].

The rich research results of many scholars have laid a solid foundation for the research of this paper, but the conclusions are not completely consistent, so this paper will carry out further research.

\section{Heoretical analysis}

According to "The industrial location theory" by Hoover, specialized agglomeration has a specific scale, corresponding to which productivity is the largest. When it is smaller than this scale, there are too few enterprises gathered to achieve the optimal external economy, and only low productivity can be obtained. When the scale is larger than this, there are too many enterprises in the agglomeration, which may, on the contrary, lead to a decline in the overall efficiency of the agglomeration for various reasons and ultimately reduce productivity. This means that a low degree of specialization increases productivity, while a high degree reduces it. The above theory is supported by a lot of research. Based on the above analysis, the hypothesis is put forward: there is an inverted U-shaped relationship between specialization agglomeration and innovation efficiency, that is, there is an optimal scale of specialization agglomeration, which maximizes the innovation efficiency of the industry.

\section{Empirical research}

\subsection{Indicator selection s}

In this paper, the panel data of the data of Chinese provinces and cities from 2003 to 2016 are used for empirical analysis. The data are from China High-tech Statistical Yearbook, and the CPI deflator is used to process the indicators.

Table1. Indicator selection

\begin{tabular}{|c|c|c|}
\hline $\begin{array}{c}\text { Explained } \\
\text { variable }\end{array}$ & $\begin{array}{c}\text { Variable } \\
\text { symbol }\end{array}$ & Variable name \\
\hline $\begin{array}{c}\text { Core } \\
\text { explanatory } \\
\text { variable }\end{array}$ & $\mathrm{AG}$ & $\begin{array}{c}\text { innovation efficiency } \\
\text { degree of specialization } \\
\text { agglomeration }\end{array}$ \\
\hline \multirow{2}{*}{ Control variable } & SIZE & firm size \\
\cline { 2 - 3 } & GOV & government support \\
\cline { 2 - 3 } & CGDP & $\begin{array}{c}\text { level of economic } \\
\text { development }\end{array}$ \\
\hline
\end{tabular}

- $\quad$ Explained variable

Innovation efficiency. The Malmquist index is used to calculate the innovation efficiency of high-tech industries (or their subsectors). Specifically speaking, this paper chooses sales income of new products as the index to measure output, and selects stock of new product development funds and full-time equivalent of $R \& D$ activity personnel as the index to measure input.
Compared with other methods, the Malmquist index method can not only obtain the conditions of different dmus at the same time point, but also obtain the efficiency evolution of dmus at different periods. As the type of data studied in this paper is panel data, it is necessary to compare and analyze the efficiency values both horizontally and vertically. Therefore, the Malmquist index method is adopted here to measure the innovation efficiency.

\section{- $\quad$ Core explained variable}

Degree of specialization agglomeration. The measurement index of professional agglomeration is an important tool for the research of industrial agglomeration and has been paid much attention by the academic circle. Combes and Overman list five conditions that should theoretically be met in the measurement of industrial agglomeration [9]: (1) comparability between industries; (2) Can control the overall agglomeration degree of economic activities; (3) Ability to control industry concentration; (4) The spatial scale change will not affect the unbiasedness of the exponent estimate; (5) Enough to conduct significance test on the estimated results. There are many measurement indicators meeting the above criteria.

As panel data are selected in this paper, the number of employees in the high-tech industry (or its subdivided industry) in each province unit land area is used to measure the degree of professional agglomeration of local industry.

\section{- Control variable}

1) Enterprise size. The ratio of the main business income of the regional high-tech industry (or its subdivided industry) to the total number of high-tech enterprises is used to measure the average size of enterprises, and the unit is 100 million yuan per unit.

2) Government support. The proportion of government funds in the total amount of funds raised for scientific and technological activities of regional high-tech industries (or its sub-industries) is used to measure the government's support for enterprise innovation.

3) Level of economic development. Regional per capita GDP is adopted to measure the economic development level, and the unit is RMB 10,000 yuan/person.

\subsection{Model selection and empirical results}

The model of this paper is as follows:

$$
\begin{gathered}
E_{i, t}=\beta_{0}+\beta_{1} * A G_{i, t}+\beta_{2} *\left(A G_{i, t}\right)^{2}+\beta_{3} * \\
S I Z E_{i, t}+\beta_{4} * G O V_{i, t}+\beta_{5} * C G D P_{i, t}+\mu_{i, t} .
\end{gathered}
$$

Tobit model was used to regression equation 1 with Stata software. The results are shown in Table 2.

Table2. Empirical results

\begin{tabular}{c|c|c}
\hline Coefficient & $\mathbf{( 1 )}$ & $\mathbf{( 2 )}$ \\
\hline $\boldsymbol{\beta}_{\mathbf{1}}$ & $0.0334^{* * *}$ & $0.0654^{* * *}$ \\
\hline $\boldsymbol{\beta}_{\mathbf{2}}$ & $-0.0005^{* * *}$ & $-0.0008^{* * *}$ \\
\hline $\boldsymbol{\beta}_{\mathbf{3}}$ & & $0.1686^{* * *}$ \\
\hline $\boldsymbol{\beta}_{\mathbf{4}}$ & & $0.2744^{* *}$ \\
\hline
\end{tabular}




\begin{tabular}{c|c|c}
\hline $\boldsymbol{\beta}_{\mathbf{5}}$ & & $0.2031^{* *}$ \\
\hline Wald & $20.33^{* * *}$ & $45.75^{* * *}$ \\
\hline Prob>F & 0.0000 & 0.0000 \\
\hline
\end{tabular}

Note :*,**,** represent significant at the level of $10 \%, 5 \%$, and $1 \%$

In Table 2, column (1) is the regression result before the addition of control variables, and column (2) is the result after the addition of control variables. According to various tests, the result of column (2) is better than that of column (1). It can be seen from column (2) that the first and second coefficient in front of agglomeration of hightech industry specialization passes the significance test at the level of $1 \%$ respectively. The first term is positive and the second term is negative, which indicates that the overall influence of the high-tech industry specialization agglomeration on the innovation efficiency presents an inverted U-shaped relationship, which proves the hypothesis.

\section{Conclusion and policy recommendations}

The research results show that there is an inverted Ushaped relationship between high-tech industry specialization agglomeration and innovation efficiency, which is promoted first and then suppressed. Therefore, there is a specialized agglomeration scale that makes innovation efficiency highest, that is, the optimal scale. Therefore, when the degree of professional agglomeration of high-tech industries is relatively low, the relevant departments should take appropriate preferential measures such as tax reduction and financial subsidies for high-tech enterprises, so as to improve the local attraction capacity, accelerate the continuous agglomeration and improve the degree of professional agglomeration. When the degree of professional agglomeration is relatively high, the above preferential measures should be gradually reduced or cancelled. High-tech enterprises should compete on a fair market and the fittest survive to appropriately reduce the degree of professional agglomeration.

\section{Acknowledgment}

I would like to extend my deep gratitude to all those who have offered selfless support in writing this paper. I am extremely grateful to my supervisor, all teachers taught me and my family members and my dear friends, whose care and support motivate me to move on and make me want to be a better person.

\section{References}

1. Lorenz, Edward, Lundvall, Bengt-Åke, Measuring Creative Work: The European Experience, IUP Journal of Knowledge Management, vol8, 2010.

2. Neng Shen, Zengyao zhao, Cluster dynamic externalities and enterprise innovation capacity, Scientific research management,vol35, pp.1-9,2014.

3. Lawrence F. Katz, Efficiency Wage Theories: A Partial Evaluation, 1986.
4. Caijiang Zhang, Jing Qin, Yuliang Zhou, Research on the influence of industrial agglomeration on regional innovation under technology diffusion effect -- from the perspective of two-stage value chain, Science of science and technology management, vol38, pp.124$132,2017$.

5. Changshi Chen, Tingting Jiang, Chenhui Liu, Empirical study on the influence of industrial agglomeration direction on urban technological innovation. Science of science,vol37, pp.77-85,2019.

6. Michael Fritsch, Viktor Slavtchev, How does industry specialization affect the efficiency of regional innovation systems? The Annals of Regional Science, vol45, 2010.

7. Yongjian Lai, Agglomeration, Spatial Dynamic Externalities and Enterprise Innovation Performance -- Based on Panel Data of Chinese Manufacturing Enterprises, Industrial Economics Research, vol2, pp.9-17,2012.

8. Shasha Li, Wenlong You. Can industrial agglomeration promote innovation in manufacturing enterprises? Research on Financial And Economic Issues, vol4,pp.30-38,2018.

9. Combes P P, Overman H G, The spatial distribution of economic activities in the European Union, Handbook of Regional \& Urban Economics, vol4, pp. 2845-2909,2006 